PRAGMATIC ASPECTS OF HUMAN COMMUNICATION 


\section{THEORY AND DECISION LIBRARY}

AN INTERNATIONAL SERIES

IN THE PHILOSOPHY AND METHODOLOGY OF THE

SOCIAL AND BEHAVIORAL SCIENCES

Editors:

Gerald Eberlein, Universität des Saarlandes

Werner Leinfel LNER, University of Nebraska

Editorial Advisory Board:

K. BorCH, Norwegian School of Economics and Business Administration

M. BUNGE, McGill University

J. S. Coleman, Johns Hopkins University

W. KROEBER-RIEL, University of Saarland

A. C. Michalos, University of Guelph

A. RAPOPORT, University of Toronto

A. SEN, University of London

W. STEGMÜLLER, University of Munich

K. SZANIAWSK I, University of Warsaw

L. TONdL, Prague

VOLUME 4 


\title{
PRAGMATIC ASPECTS \\ OF HUMAN COMMUNICATION
}

\author{
Edited by \\ COLIN CHERRY \\ Imperial College of Science and Technology, London
}

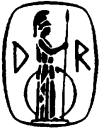

D. REIDEL PUBLISHING COMPANY

DORDRECHT-HOLLAND/BOSTON-U.S.A. 
Library of Congress Catalog Card Number 73-91427

ISBN-13: 978-90-277-0520-4

e-ISBN-13: 978-94-010-2180-7

DOI: $10.1007 / 978-94-010-2180-7$

Published by D. Reidel Publishing Company,

P.O. Box 17, Dordrecht, Holland

Sold and distributed in the U.S.A., Canada and Mexico

by D. Reidel Publishing Company, Inc.

306 Dartmouth Street, Boston,

Mass. 02116, U.S.A.

All Rights Reserved

Copyright C 1974 by D. Reidel Publishing Company, Dordrecht, Holland

No part of this book may be reproduced in any form, by print, photoprint, microfilm, or any other means, without written permission from the publisher 


\section{CONTENTS}

PREFACE

VII

JOHn C. MARSHAll AND Roger J. WALES / Pragmatics as Biology or Culture

IS A A K REVZIN / From Animal Communication to Human Speech. An Attempt at a Semiotic Analysis of the Problems of the Origins of Language

DENNIS DICKS / Experiments with Everyday Conversation

AARON V. CICOUREL / Interviewing and Memory

SOLOMON MARCUS / Fifty-Two Oppositions Between Scientific and Poetic Communication

MERRILL GARRETT / Experimental Issues in Sentence Comprehension: Complexity and Segmentation

Kenneth I. FOR S TER / Linguistic Structure and Sentence Production

J. MARSCHAK / Information, Decision, and the Scientist 


\section{PREFACE}

'Human Communication' is a field of interest of enormous breadth, being one which has concerned students of many different disciplines. It spans the imagined 'gap' between the 'arts' and the 'sciences', but it forms no unified academic subject. There is no commonly accepted terminology to cover all aspects.

The eight articles comprising this book have been chosen to illustrate something of the diversity yet, at the same time, to be comprehensible to readers from different academic disciplines. They cannot pretend to cover the whole field! Some attempt has been made to present them in an order which represents a continuity of theme, though this is merely an opinion.

Most publications of this type form the proceedings of some symposium, or conference. In this case, however, there has been no such unifying influence, no collaboration, no discussions. The authors have been drawn from a number of different countries.

The first article, by John Marshall and Roger Wales (Great Britain) concerns the pragmatic values of communication, starting by considering bird-song and passing to the infinitely more complex 'meaningful' values of human language and pictures. The 'pragmatic aspect' means the usefulness - what does language or bird song $d o$ for humans and birds? What adaptation or survival values does it have? These questions are then considered in relation to brain specialisation for representation of experience and cognition.

The second article, by Isaak Revzin of the U.S.S.R. enquires into the old question of the origins of human language. Some there may be who argue that no purpose is served by such enquiry because we cannot make experimental checks of such hypotheses. But the same comment was made by Henry Ford about history - that "History is bunk"; yet this belief does not justify the immediate dismissal of all historians.

The third article, by Dennis Dicks, a Canadian psychologist, describes procedures for making laboratory experiments upon human conversation. To me it is remarkable that conversation, which is probably the 
commonest phenomenon in nature within human experience, should be so difficult to study under laboratory conditions. Most experiments upon speech have used the utterances of single isolated persons, whilst the truly natural unit, the two-person conversation has been sadly neglected.

The fourth article, contributed by Aaron Cicourel of the U.S.A. also describes experiments into real-life communication, but this time into the highly ritualised forms we call 'interviewing' and 'fixed-choice questionnaires', techniques so commonly used in social science. In this article, it is medical interviews and questionnaires that are examined, showing the many sources of misunderstanding and error that may occur, with many illustrative examples.

Human language is infinite in its values, purposes and styles. The phenomenal thing about it is that it works. With it we may inform, insult, threaten, cajole, reconcile, conceal, move, frighten, - talk to ourselves, think and deceive ourselves. In the fifth article, by Solomon Marcus of Romania, the polar extremes of scientific language and poetic language are compared and contrasted - both belonging (in his words) "to the family of languages of discovery". It is the fact that art and science are both concerned with discovery, yet appear to be so diverse in method, that makes this comparison the more interesting.

The sixth article, by Merrill Garrett of the U.S.A., describes an experimental enquiry into the old question: "What happens when we 'understand sentences'?" Language is 'meaningful'; it works. Yet we never fully understand everything implied by a stream of speech; it can always be enlarged upon, expanded. We accept such meaning from it as suits our particular purpose of the moment. The experiments described enquire into the mental processes that may occur during perception of spoken sentences, rendering them meaningful.

Kenneth Forster, of Australia, contributes the seventh article, which is concerned with the production of sentences. As with conversation studies in the laboratory, the controlled production of spontaneous speech for experimental purposes is equally difficult. And it is the speech itself that may be observed directly, not the thoughts or intentions of the speaker which have led to its production. Some indirect approaches to the problem are described, which cast light on to the ways in which thought becomes unfolded and revealed in syntactic structures.

The eight, and final, article is by Jacob Marschak, of U.S.A., an econo- 
mist and statistician; it is entitled 'Information, Decision, and the Scientist'. This article differs somewhat from the others, inasmuch as it is concerned with extraction of information from scientific experiments. Strictly speaking we do not 'communicate' with Mother Nature (for we share no language with her) but, nevertheless, there is a great deal in common between the theory of communication and the theory of observation. We form and test hypotheses, gather evidence, infer and value in both cases (what else can we do?). The philosophical and mathematical arguments here may tell us little about the structure of language but they are more relevant to the question as to why language works.

These brief remarks are not intended as single paragraph summaries of these eight papers, nor do they necessarily express the opinions of their writers. They can do no more than vaguely illustrate the immense breadth of the field of 'human communication' and something of the great diversity of studies it has produced. Perhaps the book can do no more than indicate to students of one discipline something of the interests, of the problems, and of the methods of their fellows in other disciplines. If it does this, it will have succeeded, for nothing is more certain than that researches in any one branch of 'human communication' urgently require sympathy with the problems and purposes of other branches. 